\title{
Tumor de células gigantes de la bursa de la pata de ganso (Bursitis villonodular pigmentada extraarticular): A propósito de un caso
}

\author{
Mercedes López F. ${ }^{*}$, Begoña Canteli P.', Gotzon Iglesias H. ${ }^{1}$
}

1. Hospital Universitario de Cruces, Barakaldo, España.

Giant cell tumor of the pes anserine bursa (extraarticular pigmented villonodular bursitis): a case report

\section{Resumen:}

La sinovitis villonodular pigmentada extraarticular, también llamada tumor de células gigantes de la vaina tendinosa, es frecuente en la mano, siendo extremadamente rara su localización en la rodilla. Se presenta el caso de un paciente con una bursitis villonodular pigmentada de la bursa de la pata de ganso sin afectación intraarticular.

Palabras clave: Bursitis de la pata de ganso; Extraarticular; Sinovitis villonodular pigmentada.

\begin{abstract}
:
Extra-articular pigmented villonodular synovitis, also called giant cell tumor of the tendon seath, is common in the hand, being extremely rare in the knee. We present the case of a patient with a pigmented villonodular bursitis of the pes anserine bursa without intraarticular involvement.
\end{abstract}

Keywords: Bursitis of the pes anserine; Extraarticular; Pigmented villonodular synovitis.

López M, et al. Tumor de células gigantes de la bursa de la pata de ganso (Bursitis villonodular pigmentada extraarticular): A propósito de un caso. Rev Chil Radiol 2020; 26(3): 117-119.

*Correo electrónico: Mercedes López Ferreras / mercedes.lopezferreras@osakidetza.eus

Trabajo enviado el 10 de enero 2020. Aceptado para publicación el 20 de mayo de 2020.

\section{Introducción}

La sinovitis villonodular pigmentada es una enfermedad de la membrana sinovial de articulaciones, bursas y vainas tendinosas de causa desconocida. Se debe a una proliferación anómala benigna de histiocitos y células gigantes, con depósitos de hemosiderina ${ }^{4,6}$.

Se clasifica en función del origen en intraarticular, con afectación focal o difusa de la sinovial de la articulación (sinovitis villonodular pigmentada), y en extraarticular, con afectación de la bursa (bursitis villonodular pigmentada) o de la vaina del tendón (tenosinovitis villonodular pigmentada o tumor de células gigantes de la vaina tendinosa). Lo más frecuente es que se trate de un proceso casi exclusi- vamente intraarticular y las lesiones extraarticulares son generalmente extensiones del proceso $\mathrm{O}^{1,2,3,4,5,6,7,8}$.

La afectación de la bursa es la forma menos frecuente y la presentación exclusivamente extraarticular es excepcional, habiéndose reportado hasta el momento únicamente unos pocos casos de bursitis villonodular pigmentada de la bursa de la pata de ganso ${ }^{1,5}$.

Para un diagnóstico correcto son esenciales los hallazgos clínicos y radiográficos, siendo la resonancia magnética la técnica de imagen de elección, además del examen histológico?.

El tratamiento de elección es la resección quirúrgica, aunque existen altas tasas de recurrencia. 


\section{Presentación del caso}

Se presenta el caso de un paciente varón de 17 años, sin antecedentes de interés y ni historia de traumatismo previo, que consulta por un aumento de volumen en la cara anteromedial de la rodilla izquierda con dolor de más de un mes de evolución.

Se realiza una resonancia magnética $(\mathrm{RM})$ de rodilla izquierda con secuencias morfológicas y funcionales. En la cara interna de la rodilla izquierda, en íntima relación con los tendones de la pata de ganso, se observa una lesión quística compleja con engrosamientos parietales y proyecciones pseudonodulares de $30 \times 42 \times 80 \mathrm{~mm}$.

La lesión no muestra restricción en secuencias de difusión y tiene una captación heterogénea de contraste en las secuencias postgadolinio, tanto del componente nodular y parietal difuso como de la región nodular. Presenta asimismo efecto "blooming" en secuencias GE -T2* (Figura 1).

Las características de señal de la lesión sugieren la existencia de un tumor de células gigantes de la bursa de la pata de ganso sin afectación de estructuras intraarticulares de la rodilla. Posteriormente, ante la sospecha diagnóstica, se realiza una ecografía con toma de biopsia.

Se practicó una exéresis de la lesión mediante cirugía artroscópica y se realizó estudio anatomopatológico. En las muestras se observan proyecciones digitiformes y áreas nodulares constituidas por células redondas sin atipia, ocasionales células gigantes multinucleadas e infiltrado linfohistiocitario. Se identifican además focos hemorrágicos y abundante pigmento parduzco compatible con pigmento hemosiderótico (Figura 2). Estos hallazgos histopatológicos son compatibles con sinovitis villonodular pigmentada extraarticular.

El curso postoperatorio transcurrió sin incidencias, y el paciente evolucinó libre de síntomas de enfermedad sin déficit funcional tras la cirugía, y en seguimiento con controles evolutivos.

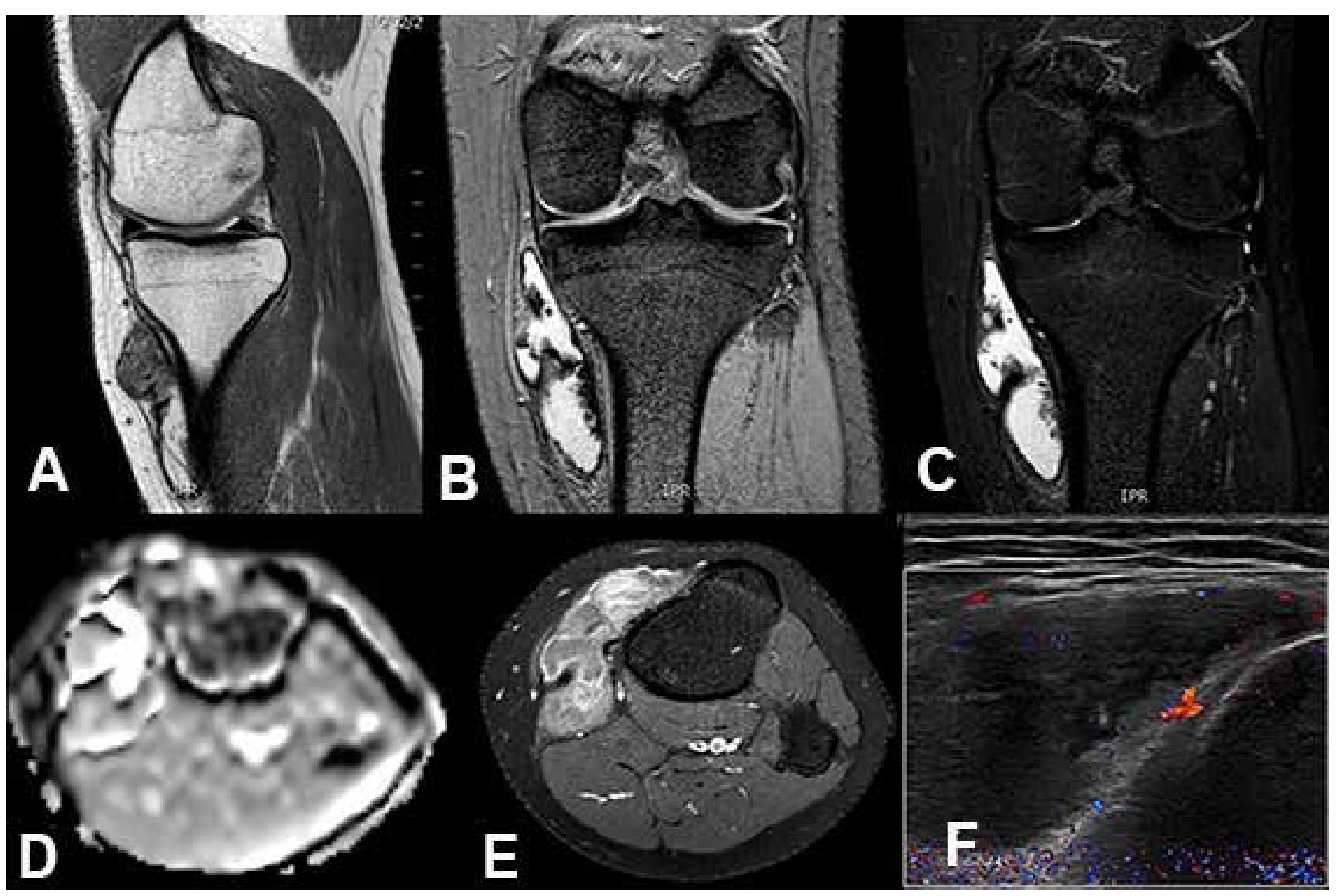

Figura 1: RM con secuencias (a) DP sagital: se observa una lesión heterógenea que sigue el trayecto de la inserción distal de los tendones de la pata de ganso; $(b, c)$ secuencias T2 FFE gradiente y STIR coronal: la lesión tiene una señal predominantemente hiperintesa con áreas hipointensas en su interior debido al depósito de hemosiderina; y (d) Mapa $A D C$ que no muestran restricción a la difusión. (e) En secuencias tras administración de Gadolinio intravenoso se muestra capitación periférica y nodular de los engrosamientos sinoviales. (f) Ecografía realizada para toma de biopsia. 


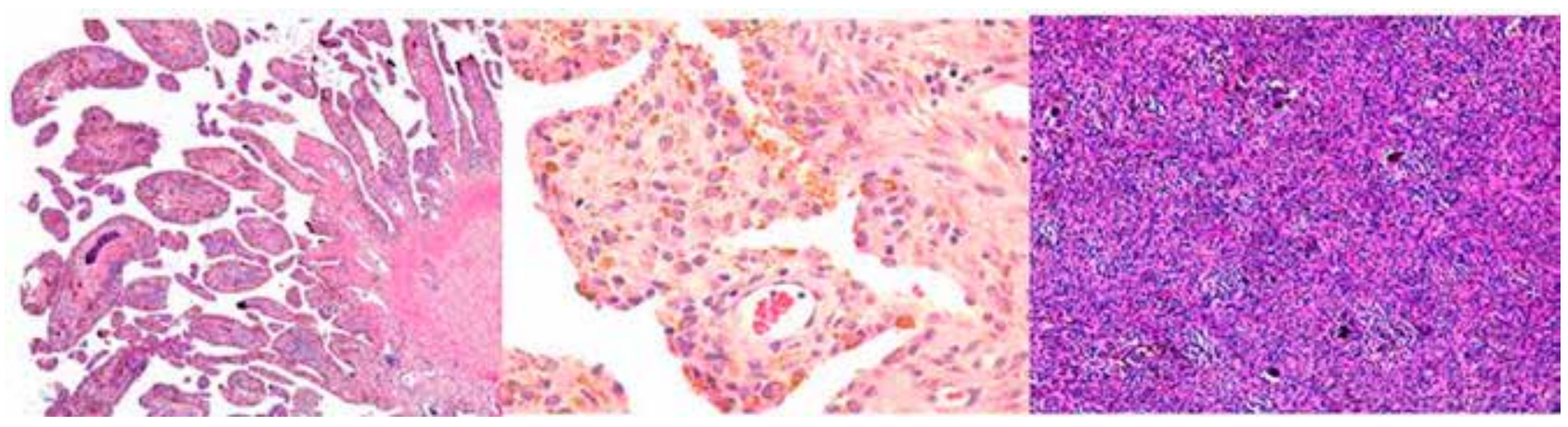

Figura 2: En las muestras histológicas se observan proyecciones digitiformes y áreas nodulares constituidas por células redondas sin atipia, células gigantes multinucleadas e infiltrado linfohistiocitario. Se identifican además focos hemorrágicos y abundante pigmento parduzco compatible con pigmento hemosiderótico.

\section{Discusión}

La bursitis villonodular pigmentada de la bursa de la pata de ganso es una forma de presentación excepcional de la enfermedad ${ }^{1,2,3,4,5,6}$.

Tiene tendencia a ocurrir en personas jóvenes, afectando a un amplio rango de edad (11-63 años), con una media de edad de 31 años sin predilección por sexo ${ }^{1,5}$.

El dolor y aumento de volumen de la rodilla generalmente de larga evolución son los síntomas más frecuentes y la limitación de la movilidad de la rodilla no es común'.

Histológicamente se visualiza una imagen multinodular de bordes bien definidos, rodeada por una pseudocápsula de colágeno compuesta por células histiocíticas mononucleares, mezcladas con células gigantes multinucleadas, células xantomatosas y células inflamatorias. Es característico de esta entidad el depósito de hemosiderina $6,7,8$.

Los hallazgos ecográficos son inespecíficos; la lesión puede ser hipo o hiperecoica, homogénea o heterogénea, con un aumento de la vascularización en el estudio con Doppler color ${ }^{2,5}$.

La RM es la técnica de elección y es útil tanto para el diagnóstico como para evaluación de la extensión, la planificación quirúrgica y el seguimiento de la enfermedad. El engrosamiento difuso y nodular de la sinovial muestra una intensidad de señal bajaintermedia en comparación con el tejido músculoesquelético en secuencias T1 y una señal de intensidad predominantemente baja en secuencias T2, debido al depósito de hemosiderina. En las secuencias eco de gradiente estas áreas presentan una menor intensidad de señal por desfase de señal (efecto "blooming"). Tras administración de contraste la lesión presenta un realce heterogéneo o de sus setpos $1,2,3,4,5,6,7,8$.

A pesar de que la literatura es escasa en el caso de la bursitis villonodular pigmentada de la pata de ganso, a diferencia de la sinovitis villonodular pigmentada, la recurrencia es escasa debido probablemente a la naturaleza localizada y extraarticular de la enfermedad. Esto permite una cirugía más agresiva con resección completa de la masa sin el riesgo de una pérdida funcional significativa de la articulación de la rodilla ni tratamientos adyuvantes como radioterapia ${ }^{1,4,5,6,7}$.

\section{Referencias}

1. Zhao H, Maheshwari AV, Kumar D, Malawer MM. Giant cell tumor of the pes anserine bursa (extra-articular pigmented villonodular bursitis): a case report and review of the literature. Case Rep Med. 2011; 2011: 491470.

2. Solomou A, Kraniotis P. Giant cell tumor of the tendon seath of the tendinous insertion in pes anserinus. Radiol Case Rep. 2017; 2: 353-356.

3. Wang C, Song RR, Kuang PD, Wang LH, Zhang MM. Giant cell tumor of the tendón seath: Magnetic resonance imaging findings in 38 patients. Oncol Lett. 2017; 13: 4459-4462.

4. Choi S, Maeng Y, Lee K, Kim D. Treatment of SportsRelated Injured Knee with Incidental Extra-articular Giant Cell Tumor of the Pes Anserinus Tendon Sheath. J Musculoskelet Disord Treat. 2017; 3: 031.

5. Kim SJ, Kang YK, Yoo CY, Kim JY. Tenosynovial Giant Cell Tumor of the Pes Anserine Bursa with Bone Marrow Extension into the Tibia: A Case Report. J Korean Soc Radiol. 2016; 75: 322-326.

6. Hepp P, Engel T, Marquass B, Aigner T, Josten C, Niederhagen $\mathrm{M}$. Infiltration of the pes anserinus complex by an extraarticular diffuse-type giant cell tumor (D-TGCT). Arch Orthop Trauma Surg. 2008; 128: 155-158.

7. Schvartzman P, Carrozza V, Pascual T, Mazza L, Odesser M, San Román JL. Caracterización imagenológica de la sinovitis vellonodular pigmentada y el tumor de células gigantes de la vaina sinovial. Rev Argent Radiol. 2015; 79: 4-11.

8. Murphey MD, Rhee JH, Lewis RB, Fanburg-Smith JC, Flemming DJ, Walker EA. From de Archives of the AFIP: Pigmented Villonodular Synovitis: Radiologic-Pathologic Correlation. Radiographics. 2008; 28: 1493-1518. 